Volume 9, No.3, May - June 2020

International Journal of Advanced Trends in Computer Science and Engineering

Available Online at http://www.warse.org/IJATCSE/static/pdf/file/ijatcse85932020.pdf

https://doi.org/10.30534/ijatcse/2020/85932020

\title{
IoT Based Approach for the Increased and Improved sales for the Brick and Mortar Stores
}

\author{
Giridhararajan $\mathbf{R}^{1}$, Shriram K Vasudevan ${ }^{2}$, $S$ Thangavelu ${ }^{3}$, Sini Raj $\mathbf{P}^{4}$ \\ ${ }_{1,2,3,4}$ Dept. of Computer Science and Engineering \\ Amrita School of Engineering \\ Coimbatore, Amrita Vishwa Vidyapeetham, India. \\ girimercury97@gmail.com, \{kv_shriram, s_thangavel, p_siniraj $\} @$ cb.amrita.edu
}

\begin{abstract}
The consistent use of smartphones in daily life has brought the wave of online shopping and digital marketing into action. Over the last few years, brick-and-mortar store owners have increasingly seen consumers migrate away from retail stores in favor of convenient and quickly accessible digital outlets. Many shoppers feel that, with the ease of smartphone and "one-click" shopping, browsing for products in a physical store is almost obsolete. However, what if the very same technology that caused this crisis in retail industry could be used to drive customers into their stores? Bluetooth Low Energy (BLE) beacons provide a great way to guide customers through a larger store and find the intended product. In addition to customer convenience, beacons are a powerful tool for storeowners to deliver targeted product recommendations. Thus, the overall solution consists of two components Proximity sensing and Product recommendation systems. When a customer comes into the proximity of a particular section of a store, the recommender system generates total and personal recommendation for the customer. The matching entries between recommended products and products from the particular section are the final optimized recommendation delivered to the customer via mobile application. Product recommendations are powered by the purchase history data of Future group stores. That way a new lease of life can be brought to struggling brick-and-mortar stores.
\end{abstract}

Key words: Internet of Things (IoT), IoT based Marketing, Proximity Marketing, Bluetooth Low Energy(BLE) beacons, Smart Retail, Smart Marketing, Recency Frequency Monetary (RFM) for marketing.

\section{INTRODUCTION}

Alternatively termed as 'hyper local marketing', proximity marketing targets valuable customers with targeted advertisements backed by the proximity of consumers (or devices) pertaining to a specific section[1]. This kindles them to take up a purchase decision in future. It powers the communication with consumers at the right place and right time with targeted, personalized and appropriate messages to their mobile phones - by welcoming at the entry areas, special in-store offers at various store sections, or receiving reviews for a newly released product. Traditional adverts on radio channels, bills and television could seem attractive, but they lack the power to drive decisions of customers to purchase products on offer or even new products[2],[3]. But, the advent of BLE beacons and other digital technology have closed the space between online and offline. Proximity sensing/ marketing with BLE beacons takes set up of a Bluetooth enabled smartphone at a designated area within the beacon range and sharing snippets in the form of text, video, images and other content via the corresponding application. In the past, brick-and-mortar shop owners have been in communication with their customers at relevant times, but the term proximity marketing got introduced to owners only in 2008. Post this, shops and stores have started sending location-powered SMS texts to mobile phones that were in proximity to a Bluetooth network and had discoverable mode for Bluetooth turned on in their devices [8],[9].

For Proof of Concept (PoC), recommendations have been derived for Big Bazaar store in Indore city. Retailers have to retarget their focus from "selling goods" to understanding and strategizing for the potential behind their brick-and-mortar stores by employing in-store enhancements like installation of proximity sensing beacons in their respective stores. Such technologies can be ably leveraged to reinvent existing convenience of physical stores over e-commerce outlets. By boosting their unique selling point, retailers can trigger the feel of buying products through touch and also upgrading the in-store convenience and ambience 


\section{EXISTING SOLUTIONS}

Connecting with customers while they near business outlets or shop and to put them into action is the main purpose of the proximity sensing and marketing[11]. Phones are a basic necessity of the 21 st century, considering that more than six billion digital phones are in the hands of customers today and while the numbers are increasingly climbing. This makes just about every consumer with a mobile-phone increasingly open to a proximity marketing strategy. Taking the case of mobile phone messaging, it's good to consider an add-on to any existing strategy. Notably, customers should not be receiving over engaging messages and would expect privacy from unexpected contact points[19].

1. BLE beacons have been integrated into the marketing campaigns by $75 \%$ of the US retailers. This has increased their profit and Return on Investment (ROI) by $9 \%$ and $175 \%$ respectively. [6]

2. By the end of 2018, 3.5 million active beacons had been in use by the retailers, as reported by Business Insider [16].

a. The report says, 'Market for Proximity Marketing,' the market value is estimated to be USD 52.46 billion by 2022, at a Compound Annual Growth Rate (CAGR) of $29.8 \%$ between 2016 and 2022 [15].

b. BLE beacon-based proximity marketing is predicted to shoot up with the highest CAGR during the forecast period.

3. 60 million customers can be expected to use BLE beacons by the end of 2019, and more than 400 million beacons are to be deployed by 2020. (Refer table 1)

Table 1: An average beacon campaign's Click Through Rate (CTR) is 25 times than that of a normal social media campaign.

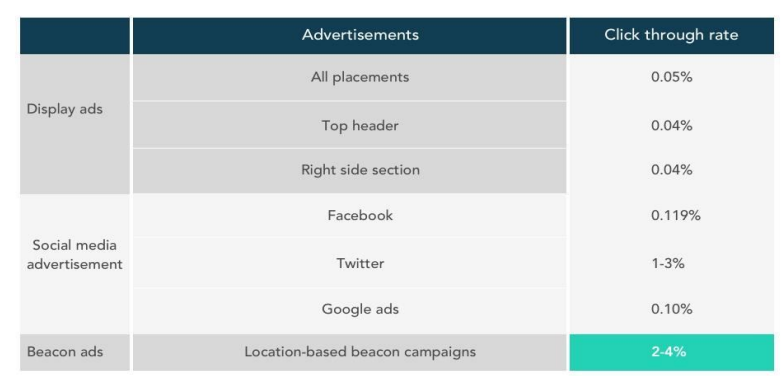

\section{PROBLEM STATEMENT}

The intention is to build proximity sensing and product recommendation systems using BLE beacons, Android and Web applications. The Android application will sense customers' proximity using beacon data and deliver customer specific recommendations. The web application will be an interface for the store owners to add/ delete/ modify product and/ or section information. The use-cases that will be covered are,
- Informing shoppers

- Enhancement of in-store sales

- Interaction and engagement with shoppers

- Helping visitors to navigate through the store

Using BLE beacons and Android/ Web technologies, details and offers of products could be seamlessly integrated in the context of a customer's proximity. Based on customers' purchase history, the offer/ product mappings are further triggered. This avoids over-invasive shopping experience while correctly engaging consumers in proximity[10][12].

\subsection{Specific Objectives}

\section{A. Proximity sensing}

Location services and Wi-Fi are used for the first level of fencing the user's proximity. Once the user enters a store, BLE beacons are used to power product updates and overall customer experience within the store [5].

B. Product recommendation

Product recommendation is achieved via,

- RFM Analysis - Signed up users get more personalized offers via their purchase preferences and history[3].

- Predictive Analysis - New users are fit into the existing model using Machine Learning (ML) and details regarding various sections of the store and offers are fetched for them[17].

\section{In-Store mapping}

In-store mapping opens room for,

- Mapping customers currently in-store - The triangulation sensing method is used to detect the exact spot of Bluetooth enabled devices.

- Collecting feedback about the store and customer interests - What routes do customers take within a store. This helps in product placement and display[18].

\section{Combination of RFM Parameters}

The combination of three parameters $\mathrm{R}, \mathrm{F}$ and $\mathrm{M}$ answers useful questions like [3]:

1. Who is the best customer?

2. Identifying customers who bought recently What if the customer buys only during the sales season?

3. Customers who buys frequently - What if a business has different plans such as monthly vs annual?[13]

4. Customers who spends the most - What if it was only once and a long time ago?

Judging the customers based on one aspect will give you an inaccurate report of the customer base and their lifetime value[14]. Hence in RFM, these three parameters are combined to create RFM score. 
Separate scores are maintained for recency, frequency and monetary factors which are combined to get the RFM score.

\subsection{Inputs for the system}

- Customer name/ ID for identification

- Recency (R) as days since last purchase: Last purchase e.g., 1 day ago, 2 days ago, etc.

- Frequency $(\mathrm{F})$ as total number of transactions e.g., How many purchases have been made over a period of time?

- Monetary (M) as the total money spent. e.g., How much money has been spent by the customer over a period of time?[20]

\subsection{Calculation of RFM scores:}

There is sufficient data about all the customer transactions/ purchases in the Future group customer database.

1. A ranking ranging between 1 to 5 (with 5 being the highest) is assigned to all the three parameters.

2. Obtained RFM values are ranked in descending order.

- For example, the most recent purchase is ranked higher (1 day ago) than the purchases made before that (1 month ago)

- Most frequent customers are ranked higher (5) than the less frequent ones (1)

- Also customers who spend more will be ranked higher (5) than the customers who spent less (1)

This scheme is called RFM technique and this has been used in the system to ensure that correct customers are reached, and also for sending recommendations to the customer(s) with appropriate products[21]

\section{ARCHITECTURE}

The product has the store-side, server-side and user-side applications to be developed. The below sections detail the same.

\subsection{Store-side}

A web-application is used by the shopkeeper to manage the offers being assigned to the products within the shop. The shopkeeper will be able to make modification on the offers and description of the products via this web application. These changes made will be reflected in real-time to the back-end database that is being maintained for this shop.

\subsection{User -side}

When the location services are enabled on the user's phone, the user will be able to receive a more precise list of offers being provided nearby. This is achieved by a technology called Geofencing. RFM analysis is then done based on user's purchase history and his/ her preferences in order to provide the user with the most appropriate offers which would be more appealing to the individual.

When location services are not enabled, but are connected to the internet through mobile network or Wi-Fi, offers can still be provided to the user, but on a more general level. RFM analysis will still be done based on the purchase history of the user and his/ her preferences, but the offer list generated would be pertaining to the region of the user instead of pin-point accurate results[23]. The Bluetooth beacons present within each shop is used to generate the discounts being offered to the products within each of their vicinities. The offers are manually assigned to each Bluetooth beacon with the help of the shopkeeper[22].

\subsection{Server-side}

AWS EC2 Ubuntu Instance acts as the server with a Cassandra database. Flask development server is used for APIs to interface with database and provide recommendations [7]. The user flow is presented below as figure 1. Also, the store owner workflow is presented below as figure 2 .

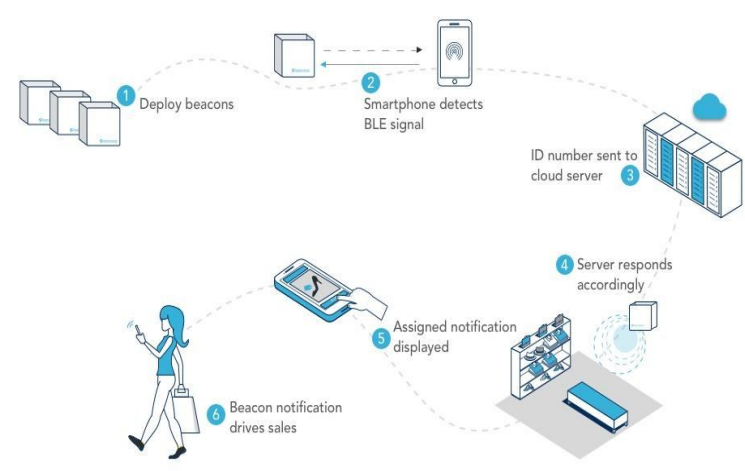

Figure 1: User flow

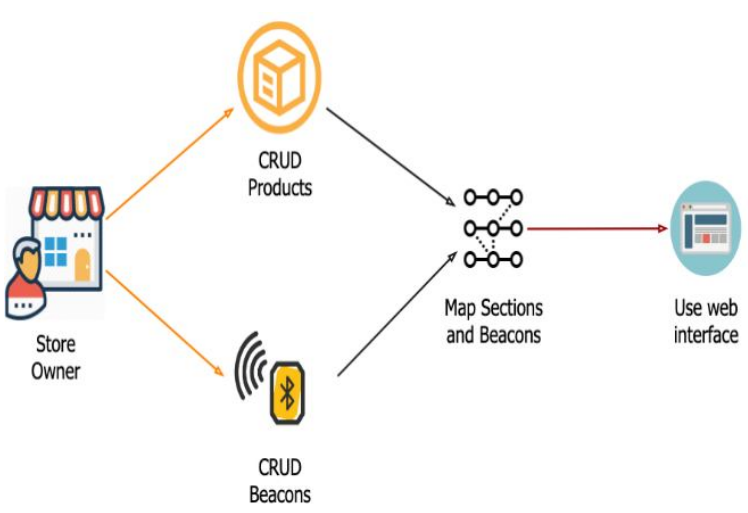

Figure 2: Store owner flow

The technical architecture is displayed in figure 3. One can have a clear view of the entire system through the figure. 


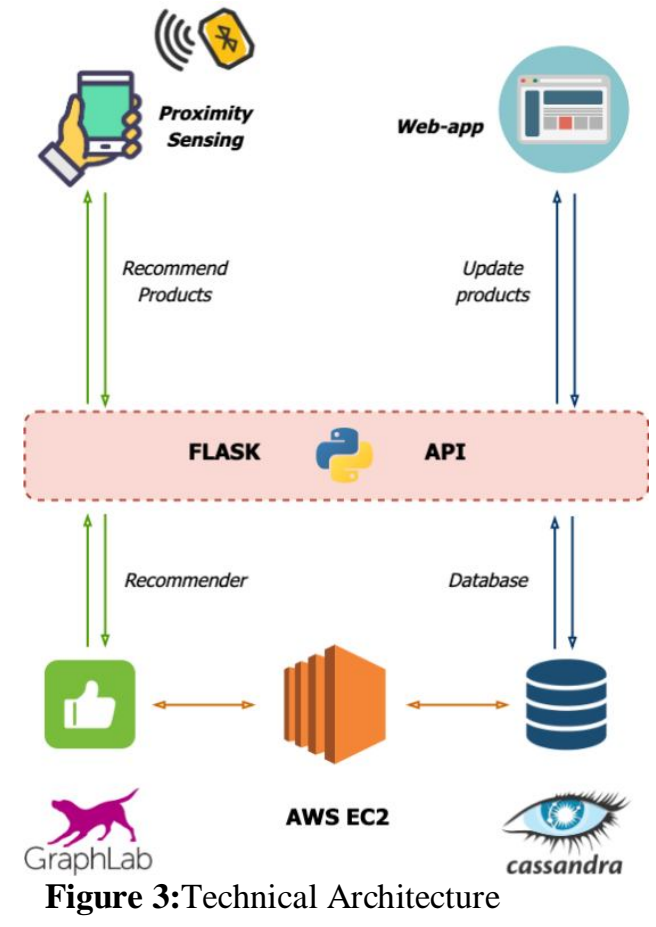

\section{RESULTS}

Once the buyer/ potential buyer enters the mall, the android application developed shall provide the details of the beacons available in the mall. The names of the beacons can be the names of the stores. Here, in the below figure 4, the name of the beacon is revealed as mint. Since this is an experimental setup and PoC development, we tested the same with one beacon. The grid view for a single shop is presented below as figure 4 .

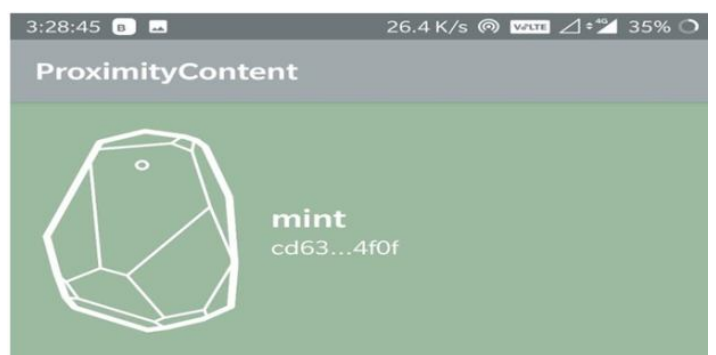

Figure 4:Beacon details in a grid view for a single shop.

On clicking the beacon icon, the offers and recommended products shall be presented immediately to the user. The application would show the recommendation list for a particular customer pertaining to a particular shop as displayed figure 5[4]. This includes recommendation and suggestions based on previous purchases as well. The recommendation is made through RFM analysis and the same can be visualized from the software aspect in the figure 5 [24].

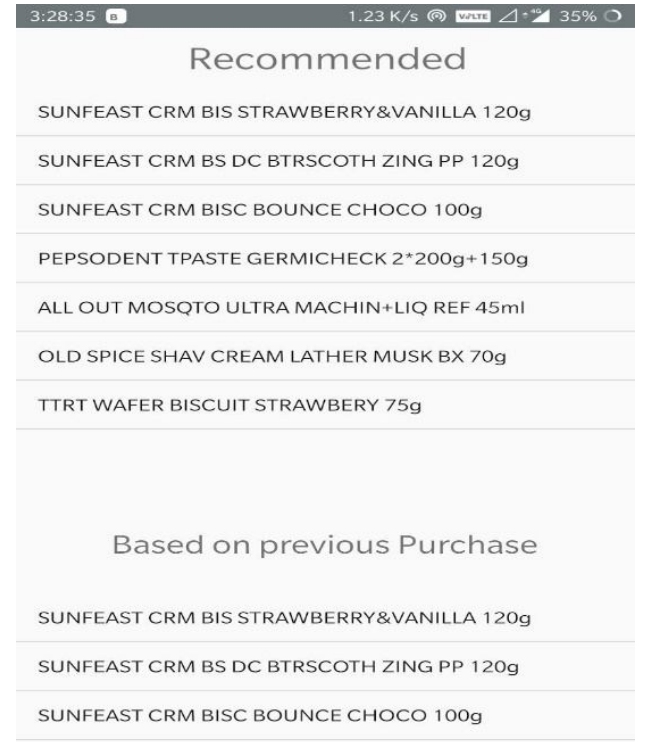

Figure 5:The Recommendations

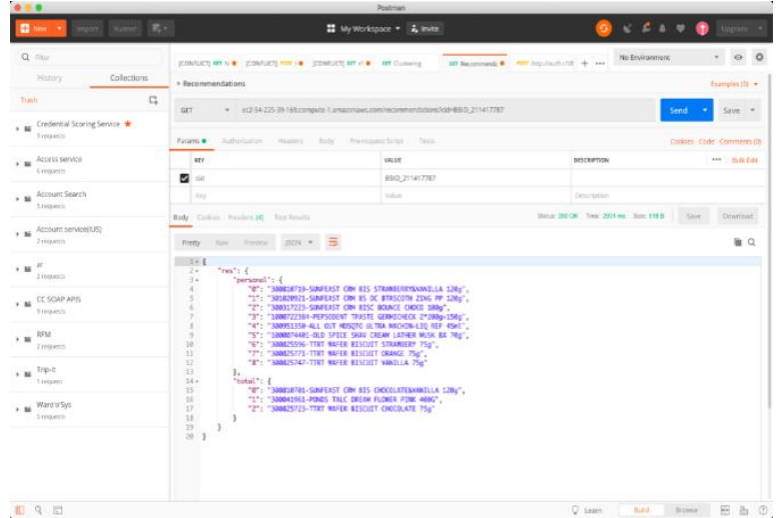

Figure 6:Postman screenshot

\section{CONCLUSION}

In the past, brick-and-mortar shop owners have been in contact with their customers at relevant times, but the term proximity marketing got introduced to them only in 2008. Post this, shops and stores started sending location-powered SMS texts to mobile phones that were in proximity to a Bluetooth network and had discoverable mode for Bluetooth turned on in their devices. This system makes use of RFM analysis, which is a marketing technique that determines recency, frequency and monetary details of the customer, which increases the sales of the store.

The future scope and challenges for this strategy lie in tackling a few questions as follows[25]:

1. How can a new customer fit into the current model?

Solution: Demographics based prediction and recommendation can be a start to this.

2. How to avoid invasive experience?

Solution: Churn Analysis could be adopted to address such problems. Finally, on the app-side, quick querying and real-time experience is expected. For this, a combination of robust server-side and a progressive front-end is necessary. 
There is a lot of room for growth and developments in the same product. Adding machine learning concepts shall be making this application more versatile and accurate.

\section{REFERENCES}

1. Rodrigues, Fátima, and Bruno Ferreira. "Product recommendation based on shared customer's behaviour." Procedia Computer Science (2016).

https://doi.org/10.1016/j.procs.2016.09.133

2. Deldjoo, Yashar, Mehdi Elahi, Massimo Quadrana, and Paolo Cremonesi. "Toward building a content-based video recommendation system based on low-level features." In International Conference on Electronic Commerce and Web Technologies, pp. 45-56. Springer, Cham, 2015.

https://doi.org/10.1007/978-3-319-27729-5_4

3. Dias, M. Benjamin, Dominique Locher, Ming Li, Wael El-Deredy, and Paulo JG Lisboa. "The value of personalised recommender systems to e-business: a case study." In Proceedings of the 2008 ACM conference on Recommender systems, pp. 291-294. 2008. https://doi.org/10.1145/1454008.1454054

4. Online:

https://www.hackerearth.com/challenge/competitive/fut ure-datathon-1

5. Online:

https://docs.aws.amazon.com/AWSEC2/latest/UserGuid e/instance-types.html

6. Online:

https://blog.beaconstac.com/2018/07/proximity-marketi ng-in-2018-and-the-market-forecast-for-2022

7. Online:https://community.estimote.com/hc/en-us/articles /204092986-Technical-specification-of-Estimote-Beaco ns-and-Stickers

8. Poncin, Ingrid, and Mohamed Slim Ben Mimoun. "The impact of "e-atmospherics" on physical stores." Journal of Retailing and Consumer Services 21, no. 5 (2014): 851-859.

9. Zhang, Kem ZK, and MoradBenyoucef. "Consumer behavior in social commerce: A literature review." Decision Support Systems 86 (2016): 95-108. https://doi.org/10.1016/j.dss.2016.04.001

10. Kowatsch, Tobias, and Wolfgang Maass. "In-store consumer behavior: How mobile recommendation agents influence usage intentions, product purchases, and store preferences." Computers in Human Behavior 26, no. 4 (2010): 697-704.

11. Enders, Albrecht, and TawfikJelassi. "The converging business models of Internet and bricks-and-mortar retailers." European Management Journal 18, no. 5 (2000): 542-550.

12. Oh, Jungmi, Susan S. Fiorito, Hira Cho, and Charles F. Hofacker. "Effects of design factors on store image and expectation of merchandise quality in web-based stores." Journal of Retailing and Consumer Services 15, no. 4 (2008): 237-249.

https://doi.org/10.1016/j.jretconser.2007.03.004
13. Zhang, Kem ZK, and MoradBenyoucef. "Consumer behavior in social commerce: A literature review." Decision Support Systems 86 (2016): 95-108.

14. Mobasher, Bamshad, Robert Cooley, and Jaideep Srivastava. "Automatic personalization based on web usage mining." Communications of the ACM 43 , no. 8 (2000): 142-151.

https://doi.org/10.1145/345124.345169

15. Yao, Lina, Quan Z. Sheng, Anne HH Ngu, Helen Ashman, and Xue Li. "Exploring recommendations in internet of things." In Proceedings of the 37th international ACM SIGIR conference on Research \& development in information retrieval, pp. 855-858. 2014.

16. Zhang, Yiyang, and Jianxin Roger Jiao. "An associative classification-based recommendation system for personalization in B2C e-commerce applications." Expert Systems with Applications 33, no. 2 (2007): 357-367. https://doi.org/10.1016/j.eswa.2006.05.005

17. McDonald, David W., and Mark S. Ackerman. "Expertise recommender: a flexible recommendation system and architecture." In Proceedings of the 2000 ACM conference on Computer supported cooperative work, pp. 231-240. 2000.

18. Hadikusumo, B. H. W., SatapornPetchpong, and ChotchaiCharoenngam. "Construction material procurement using Internet-based agent system." Automation in Construction 14, no. 6 (2005): 736-749.

19. Rose, Gregory M., Detmar W. Straub, and John D. Lees. "The Effect of Download Time on Consumer Attitude Toward the Retailer in eCommerce." AMCIS 2000 Proceedings (2000): 439.

20. Tarnowska, Katarzyna, Zbigniew W. Ras, and Lynn Daniel. "Customer Attrition Problem." In Recommender System for Improving Customer Loyalty, pp. 113-122. Springer, Cham, 2020. https://doi.org/10.1007/978-3-030-13438-9_9

21. Gohari, Faezeh Sadat, Fereidoon Shams Aliee, and Hassan Haghighi. "A significance-based trust-aware recommendation approach." Information Systems 87 (2020): 101421.

22. Dey, AmlanJyoti, and Hiren Kumar Deva Sarma. "Routing Techniques in Internet of Things: A Review." In Trends in Communication, Cloud, and Big Data, pp. 41-50. Springer, Singapore, 2020.

23. Gautam, Prateek Raj, Sunil Kumar, AkshayVerma, Tarique Rashid, and Arvind Kumar. "Localization of Sensor Nodes in WSN Using Area Between a Node and Two Beacons." In Advances in VLSI, Communication, and Signal Processing, pp. 221-228. Springer, Singapore, 2020.

24. Patil, Shamshekhar S., and ArunBiradar. "Novel authentication framework for securing communication in internet-of-things." International Journal of Electrical \& Computer Engineering (2088-8708) 10 (2020).

25. Saini,.K,Akanksha Aggarwal, Sunita Saini.,"Challenges in the Area of IoT,"In Handbook of Research on the Internet of Things Applications in Robotics and Automation, pp. 87-105,IGI Global,2020. 